\title{
Immunological targets for cancer therapy: new recognition
}

This article was published in the following Dove Press journal:

ImmunoTargets and Therapy

\author{
Michael R Shurin ${ }^{1,2}$ \\ 'Department of Pathology, University \\ of Pittsburgh Medical Center, \\ Pittsburgh, PA, USA; ${ }^{2}$ Department of \\ Immunology, University of Pittsburgh \\ Medical Center, Pittsburgh, PA, USA
}

Correspondence: Michael R Shurin Department of Pathology, University of Pittsburgh Medical Center, Pittsburgh, PA, USA

Email shurinmr@upmc.edu
During the last decade, we have witnessed exhilarating progress in the expansion of immunotherapeutic approaches to cancer treatment. In part, this has been because of discovery and development of antibodies which can block immune inhibitory receptors unleashing antitumor immune responses - the so-called checkpoint inhibitors. Blocking cancer progression by eliminating brakes on immune effector cells in the tumor environment has jointly earned James P Allison, $\mathrm{PhD}$ (Department of Immunology, MD Anderson Cancer Center, University of Texas, Houston, TX, USA) and Tasuku Honjo, MD, PhD (Graduate School of Medicine, Kyoto University, Kyoto, Japan) the Nobel Prize in Physiology or Medicine in 2018. Whereas the concept of cancer immunosurveillance dates back more than 100 years, the study of Allison's and Honjo's teams over the past few decades not only confirmed the idea but also converted it into an effective immunotherapeutic tactic, which dramatically improved outcomes for some cancer patients.

There are several central and peripheral protective regulatory mechanisms developed by the immune system to prevent collateral damage during active immune response to pathogens and establish immune tolerance for blocking autoimmune and autoinflammatory reactions. Included in these defensive pathways are the growing family of inhibitory receptors and corresponding signaling networks, known as "immune checkpoint pathways". Expression of these inhibitory receptors is upregulated on lymphocytes during the development of active immune responses, which creates a negative feedback mechanism critical for immunosuppression and prevention of an overenergetic inflammatory reaction.

Though these immune inhibitory cycles operated by checkpoint pathways are critical in precluding disproportional inflammation, they are also a part of an enormous immunological arsenal utilized by growing malignant tumors to highjack the immune response and escape from immune recognition and elimination. The Nobel assembly at the Karolinska Institute honored Allison's and Honjo's effort on turning immune inhibitory receptors into effective therapeutic targets.

Allison discovered that CTLA-4 (also known as CD152) functioning as an immune checkpoint, that is, being a negative regulator of $\mathrm{T}$ cell activation, blocks the ability of cytotoxic T cells to attack and eliminate tumors. Allison's laboratory developed an antibody against CTLA-4 and reported in 1996 that injecting anti-CTLA-4 antibodies into mice eradicated colorectal carcinoma tumors. ${ }^{2,3,6}$ This work led to the development 
of Bristol-Myers Squibb's (New York, NY, USA) drug Yervoy for advanced forms of melanoma. In 2011, the US Food and Drug Administration (FDA) approved ipilimumab, sold under the brand name Yervoy, to treat melanoma. Currently, Yervoy is under testing for its ability to treat colorectal and kidney cancers. Today, another biotech company Agenus works on many specifics for their proprietary CTLA-4-related drugs and develops a trial involving angiosarcoma and cervical cancer.

In parallel, Honjo was working on another immune checkpoint PD-1. His team identified the PD-1 receptor on the surface of T cells in 1992 and showed that it played an important role in tumor escape. ${ }^{1,4,5}$ In 2005, Honjo et al reported the effect of PD-1 blockade on the spread of melanoma and colon cancer cells in mice. ${ }^{7}$ Interestingly, anti-PD-1 antibodies have been shown to display even more dramatic effects than anti-CTLA-4 antibodies helping patients with spreading or metastatic cancer, that is, previously untreatable tumors. In 2014, the FDA approved the first "PD-1 blockade" antibodies, pembrolizumab (Keytruda; Merck, Kenilworth, NJ, USA) and nivolumab (Opdivo; Bristol-Myers Squibb), both initially approved for the treatment of melanoma. Nowadays, there are several antibodies against both PD-1 and its ligand PD-L1 on malignant and/or immune regulatory cells that are approved for treatment of patients with melanoma, non-small-cell lung cancer, kidney cancer, bladder cancer, head and neck cancers and Hodgkin's lymphoma.

The Immunotargets and Therapy journal congratulates Allison and Honjo on award of the 2018 Nobel Prize in Physiology or Medicine for their pioneering work on immune checkpoint blockade therapy that has revolutionized cancer therapies and medicine. Their work has reformed our understanding of how the immune system identifies malignant cells and has formed a paradigm shift in clinical tumor immunology and oncology that should likely modify how we treat cancer for the future.

There are several interesting publications of special significance in the Immunotargets and Therapy journal focusing on immune checkpoint inhibition therapy. For instance, Shine Raju, Ranjit Joseph and Sameep Sehgal in their "Review of checkpoint immunotherapy for the management of non-small cell lung cancer" published 31 July 2018 (volume 2018:7, pages 63-75) comprehensively describe PD-1 inhibitors, nivolumab and pembrolizumab, and PD-L1 inhibitor, atezolizumab, that have been approved for the treatment of advanced non-small-cell lung carcinoma (NSCLC). The authors provide a detailed review of these newer agents, the mechanism of action of these agents, their side-effect profiles, therapeutic indications as well as current evidence supporting their use in the management of NSCLC.

Next, Jennifer M Yoest in a short review "Clinical features, predictive correlates, and pathophysiology of immunerelated adverse events in immune checkpoint inhibitor treatments in cancer" published October 10, 2017 (volume 2017:6, pages 73-82) discusses known immune-related adverse events encountered during treatment of cancer patients with immune checkpoint inhibitors that are likely mediated via abnormal immune activation and can manifest with a variety of symptoms resembling autoimmunity. The author discusses many case reports aiming to inform the clinicians, researchers and health care professionals of the scope of organ systems affected, the severity of the conditions being encountered, and the responses of these events to treatment. She also explores the use of immune checkpoint inhibitors in the setting of preexisting autoimmunity and considers the ability to detect autoantibodies before and during immunerelated adverse events to correlate their levels with clinical outcomes. These data will definitely play an important role in future research and clinical practice.

Finally, Marianne Davies and Emily A Duffield in "Safety of checkpoint inhibitors for cancer treatment: strategies for patient monitoring and management of immune-mediated adverse events" published August 24, 2017 (volume 2017:6, pages 51-71) also educate the readers on the current knowledge about immune-mediated adverse event associated with checkpoint inhibitor treatment, including strategies and tools for the prompt identification, evaluation and optimal management of these events. The authors stress that although most adverse effects are mild and easily managed, early identification and proactive treatment are essential actions serving both to reduce the risk of developing severe outcomes and to maximize the potential for patients to receive the benefits of ongoing immunotherapy.

\section{Disclosure}

The author reports no conflicts of interest in this work.

\section{References}

1. Ishida Y, Agata Y, Shibahara K, Honjo T. Induced expression of PD-1, a novel member of the immunoglobulin gene superfamily, upon programmed cell death. EMBO J. 1992;11(11):3887-3895.

2. Leach DR, Krummel MF, Allison JP. Enhancement of antitumor immunity by CTLA-4 blockade. Science. 1996;271(5256):1734-1736.

3. Kwon ED, Hurwitz AA, Foster BA, et al. Manipulation of T cell costimulatory and inhibitory signals for immunotherapy of prostate cancer. Proc Natl Acad Sci U S A. 1997;94(15):8099-8103. 
4. Nishimura H, Nose M, Hiai H, Minato N, Honjo T. Development of lupuslike autoimmune diseases by disruption of the PD-1 gene encoding an ITIM motif-carrying immunoreceptor. Immunity. 1999;11(2):141-151.

5. Freeman GJ, Long AJ, Iwai Y, et al. Engagement of the PD-1 immunoinhibitory receptor by a novel B7 family member leads to negative regulation of lymphocyte activation. $J$ Exp Med. 2000;192(7): $1027-1034$.
6. Hodi FS, Mihm MC, Soiffer RJ, et al. Biologic activity of cytotoxic T lymphocyte-associated antigen 4 antibody blockade in previously vaccinated metastatic melanoma and ovarian carcinoma patients. Proc Natl Acad Sci U S A. 2003;100(8):4712-4717.

7. Iwai Y, Terawaki S, Honjo T. PD-1 blockade inhibits hematogenous spread of poorly immunogenic tumor cells by enhanced recruitment of effector T cells. Int Immunol. 2005;17(2):133-144.

Dove Medical Press encourages responsible, free and frank academic debate. The content of the ImmunoTargets and Therapy 'Editorial' section does not necessarily represent the views of Dove Medical Press, its officers, agents, employees, related entities or the ImmunoTargets and Therapy editors. While all reasonable steps have been taken to confirm the content of each Editorial, Dove Medical Press accepts no liability in respect of the content of any Editorial, nor is it responsible for the content and accuracy of any Editorial.

\section{Publish your work in this journal}

ImmunoTargets and Therapy is an international, peer-reviewed open access journal focusing on the immunological basis of diseases, potential targets for immune based therapy and treatment protocols employed to improve patient management. Basic immunology and physiology of the immune system in health, and disease will be also covered. In addition, the journal will focus on the impact of manage-
Dovepress

ment programs and new therapeutic agents and protocols on patient perspectives such as quality of life, adherence and satisfaction. The manuscript management system is completely online and includes a very quick and fair peer-review system, which is all easy to use. Visit http://www.dovepress.com/testimonials.php to read real quotes from published authors.

Submit your manuscript here: http://www.dovepress.com/immunotargets-and-therapy-journal 